\title{
ADOPTION OF MODULAR DESIGN BY MAKERS AND PROSUMERS. A SURVEY
}

\author{
Asión-Suñer, Laura; \\ López-Forniés, Ignacio
}

Universidad de Zaragoza

\begin{abstract}
The growing tendency for end users to get involved in the design and manufacturing phase of their own products has led to the proliferation of makers and prosumers. The tools available for this have been adapted to be used by non-specialized users who seek to meet their own needs and wants. Modular design offers a series of advantages directly related to the needs of current users, but which has hardly been used to benefit them. Instead, its development has geared towards aspects that are hidden to the consumer, such as flexible production.

This work presents a survey, part of a wider research, whose objective is to develop a methodological model for the prosumer to benefit from modular design. The survey was open for several months and was only aimed at makers, prosumers and designers. A dissemination plan was drawn up where the current communication channels of these users were taken into account. The results show what the current prosumer is like, what their needs are and how they relate to modular design. Finally, the conclusions provide information on how to develop a model proposal to ensure its correct usability and acceptance.
\end{abstract}

Keywords: Modular design, Prosumer, Design methods, New product development, User centred design

\section{Contact:}

Asión-Suñer, Laura

Universidad de Zaragoza

Department of Design and Manufacturing Engineering

Spain

lauraasion@gmail.com

Cite this article: Asión-Suñer, L., López-Forniés, I. (2021) 'Adoption of Modular Design by Makers and Prosumers. A Survey', in Proceedings of the International Conference on Engineering Design (ICED21), Gothenburg, Sweden, 16-20 August 2021. DOI:10.1017/pds.2021.36 


\section{INTRODUCTION}

Evolution in consumer habits is one of the main social challenges that product designers and makers must deal with. Certain factors such as circular economy or new technologies are conditioning the way in which products and services are designed (den Hollander et al., 2017). In this regard, there is a tendency for end users to get involved in the design and manufacturing phase of their own products, leading to phenomena such as the growing current maker (Papavlasopoulou et al., 2017). In the same way, the tools available for this have evolved and have been adapted to be used by non-specialized users who seek to create their own solutions (Asión-Suñer and López-Forniés, 2020). These solutions respond to latent needs that may appear before acquiring the product or during its life cycle, giving rise to the search by the user for adaptable and customizable products that are even capable of growing (Zheng et al., 2017). It is necessary to adapt the design process to these new users who seek to create their own products, whether as a hobby or necessity, through the evolution of the resources that we already have.

Some technologies, such as Arduino or 3D printing, have become popular among users for their easy access and usability (Souza and Sato, 2019). However, there are still design methods that could satisfy these users but have not evolved in this direction. This is the case of modular design, the design based on independent and connectable modules that allow the variability of a product. It offers advantages related to the needs of current users as it has already seen in some examples (Swidget, 2020) (Fairphone, 2020). Nonetheless, its development has been geared towards flexible production and reducing manufacturing times and costs (Favi and Germani, 2012) (AlGeddawy and ElMaraghy, 2013) (You and Smith, 2016), aspects that are hidden from the consumer's eyes. Therefore, currently the modular design rarely meets the needs of the user that occur in the life cycle of the product, such as maintenance or updates. When it does, it is in a superficial way that responds more to an aesthetic than a functional aspect. Modular design can offer much more, so we must study the current consumer and observe the trends of the users with the aim of providing products that adapt to the current context.

This work presents a survey that is part of a doctoral thesis whose objective is to develop a methodological model to design modular products focused on prosumer users, those who assume the role of producer and consumer getting involved in the design, manufacturing or assembly process of their own products (Toffler, 1980). Previous work carried out under this line of research shows that modular design has a series of intrinsic characteristics that provide benefits to products related to the needs of prosumers and makers, such as adaptability or customization (Asión-Suñer and LópezForniés, 2019). Nevertheless, no modular design method developed to date focuses on these users, so there are no previous studies that analyse the current and potential relationship of makers and prosumers with modular design. On the other hand, the methods found are aimed at specialized profiles without taking into account the end users who could benefit from them and the subsequent usability that they will give to the product. Before this context, we hypothesize if a field study focused on the end user will help us to obtain a series of conclusions that ensure the success of the methodological model. To approach it correctly, we formulate the following research questions: Do these users currently use modular design? Do they follow any design method? Would they be willing to use the method to be developed?

The field study in which this survey is framed analyzes what the prosumer is like currently and their environment with the aim of knowing their main needs. In addition to the survey, the study also included interviews with experts and attendance at a maker event (Maker Faire Bilbao, 2019). The conclusions obtained in the interviews offered macro level information about the prosumer and its potential relationship with modular design. These answers inquire into the philosophy and trends of this sector from an abstract point of view that provides information about what the user is like and how we should approach him. On the other hand, conducting a global survey focused on the same users provides information at a micro level on how to develop the methodological model to ensure its correct usability and acceptance. Thus, the survey was formulated with the main objective of obtaining information that would reveal the requirements to create a methodological model of modular design for the prosumer. Prosumer is an emergent group linked to I4.0 that may vary the future market expectations. This survey can reveal how prosumers and makers are currently using modular design, showing what the model should look like. These results can contribute to the design research domain interested in prosumers, including companies seeking to obtain prosumers' characteristics. The results can also be applied in creating other prosumer-focused design methods. 
The survey was open for several months and was only aimed at users who were fond of creating, modifying, redesigning or customizing their own products, such as makers or designers. Otherwise, a dissemination plan was drawn up so that the survey reached the maximum number of respondents possible with the aim that their answers were agreed upon, providing truthfulness to the final results. For this, the current communication channels of these users were taken into account and we collaborated with associations and maker groups, not only at the local and national level, but also worldwide.

\section{METHODOLOGICAL DESCRIPTION}

In order for the results to be detailed and well defined, each individual question was posed to be quantitatively analyzed. In this way, the survey is structured around four main questions:

- Defining the figure of the prosumer, to know its terminology, behaviour and objectives.

- Establishing the characteristics of modular design, to find out how respondents use it, for what, how often and if they understand the term correctly, taking advantage of its benefits.

- Knowing the use of design methodologies, to analyse what basic methods they use in their projects, if they already use design methods and in which aspects of the product they work.

- Identifying how is real and potential application of modular design in the prosumer field.

To ensure that the survey was only completed by users who were related to prosumer field (makers, product designers, etc.), a verification question was introduced at the beginning of the survey. Thus, if the respondent didn't belong to any maker organization (either physical or a digital) and wasn't a designer, the survey ended. The fact that the survey was focused on such a specific type of user made it difficult to disseminate it. Only responses from prosumers, makers or designers were accepted, so many users were discarded from the beginning. For this reason, it was of great importance to plan the dissemination process through the channels frequented by the target user to reach the largest number of prosumers possible. These channels were identified thanks to the previous investigation carried out, reinforced by the interviews with experts, that confirmed which were the most common communication channels. Thus, the dissemination strategy began with a series of basic steps to which new actions were added according to the results that were obtained. Taking into account the high level of communication and collaboration between makers, a good way to start with the dissemination of the survey was by sharing it among maker associations and for these, in turn, to send it to their members.

The first step was to send the survey to national prosumer experts who had previously been contacted to be interviewed. Most were part of or directed makerspaces or associations and belonged to maker groups among which they disseminated the survey. After attending the Maker Faire Bilbao 2019, we also sent the survey via email to the organizations that were contacted there. It was considered to send the survey to other associations, but it was discarded after achieving better results through dissemination to interviewees. After this, the first part of the dissemination was concluded, reaching various groups and associations both local and national. Due to the presence of makers in social networks and forums, the dissemination continued through these channels. First on Twitter, where the highest participation was obtained until then. Given the high rate of national responses, dissemination continued through maker groups present on other social networks and digital platforms for dissemination worldwide.

Therefore, despite that initially the survey only contemplated a national dissemination, two more versions were developed: one aimed at users in Latin America and the other worldwide. The objective was to analyse whether the results varied as the origin of the users changed. The global version of the survey differed from the other two in that it was not directed only at maker users, but also at professional designers. This profile can also provide relevant information to these issues and many of the platforms users are designers. After finishing the dissemination on social networks, the survey was shared on the most common digital platforms where makers and designers share projects. Finally, the survey was sent by email to multiple organizations of industrial design professionals in different countries. After following the diffusion process, the sample of results obtained was larger than expected.

After finishing the survey, the most effective communication channels according to each version were:

- National (Spain): Twitter. The spread on Twitter began when two of the interviewees tweeted the survey on their personal profiles. This resulted in being retweeted by other public profiles with numerous followers, thus reaching many more users.

- Latin America: Facebook Groups. Despite the fact that this version of the survey was also shared at the $X V$ Encuentro Latinoamericano de Diseño, the most effective responses were those obtained in Facebook groups dedicated to maker culture. 
- World: Thingiverse Groups. Due to the format and rules of other forums, the most effective in reaching the largest number of survey participants was Thingiverse. The main reason is that on other websites the survey could only be shared once.

The dissemination strategy is summarized in the following infographics:
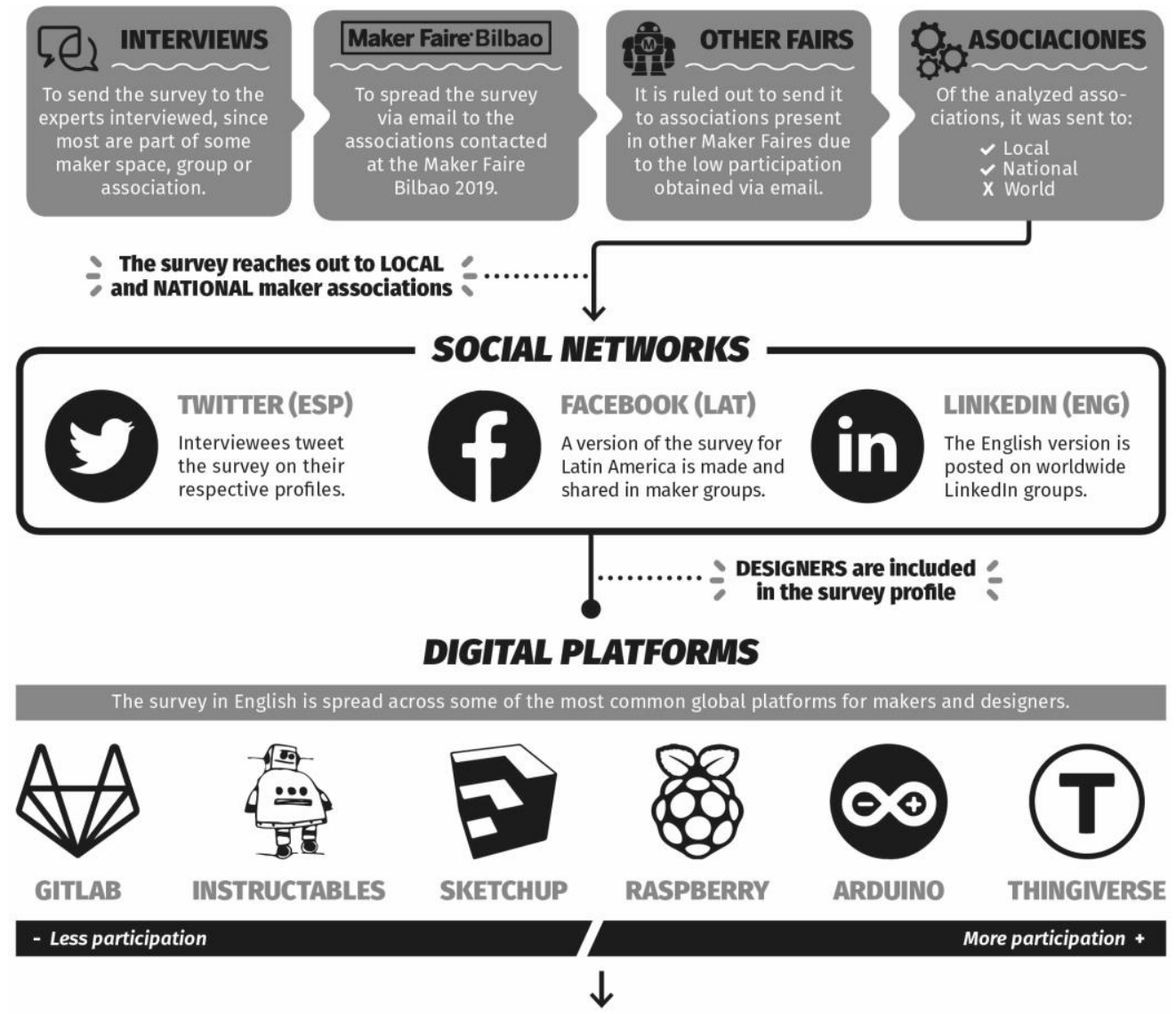

WORLDWIDE DESIGN ORGANIZATIONS

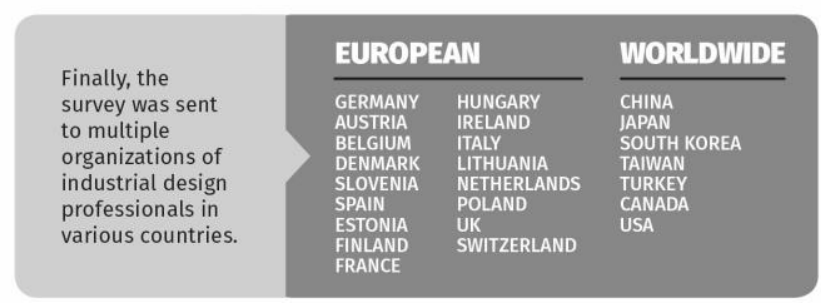

Figure 1. Infographic of the dissemination strategy.

Finally, a report was developed with the results of the survey, detailing all the responses to the questions. The report was sent to all respondents who provided their email, as well as the experts interviewed who collaborated in its dissemination. The document also included other relevant information such as the objective of the survey, the line of research in which it is framed and the scope it obtained.

\section{RESULTS}

A total of 289 responses were obtained: 124 nationally (Spain), 142 worldwide and 23 in Latin America. The survey was conducted in 34 different countries, among which the highest number of responses was obtained in Spain (135), USA (40) and Germany (15). Regarding the profiles of the respondents, in the Spanish and Latin American versions the survey was directed only at makers. However, in the world version, 58\% were designers compared to $37 \%$ who were makers. Furthermore, the majority of respondents were familiar with both physical and virtual maker organizations $(63 \%$ in Spain, $87 \%$ in the world and 39\% in Latin America). Among them, the most cited were Thingiverse, particular Makerspaces and Fablabs, Arduino and Cults 3D. Below is a summary of the results obtained. These have been divided according to the main structure of the survey. 


\subsection{The figure of the prosumer}

This section presents the results of the block of the survey that deals with the figure of the prosumer.

\subsubsection{How do you call users who create, modify, redesign or customize their own products?}

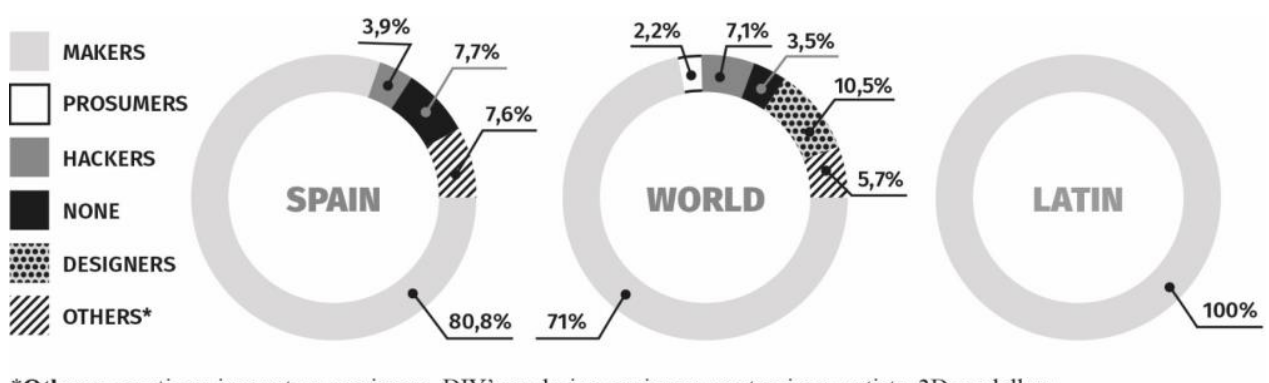

*Others: creatives, innovators, engineers, DIY'ers, design engineers, customizers, artists, 3D modellers.

Figure 2. Terminology around the figure of the prosumer.

\subsubsection{What does the term "prosumer" mean to you?}
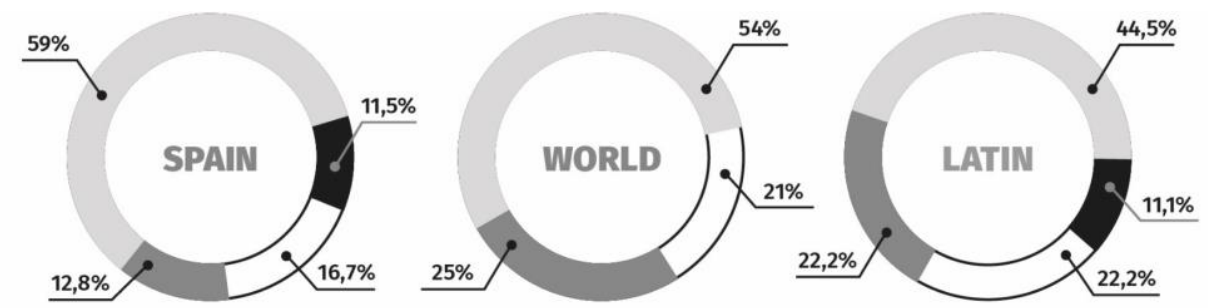

Defender of a brand that generates content about it through the use of various communication channels

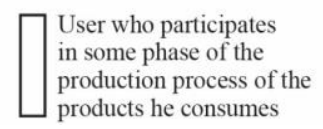
Semi-professional consumer who
gets informed about the products
he consumes and uses complex he consumes and uses complex
equipment destined to professionals

Figure 3. Meaning of "prosumer" according to respondents.

\subsubsection{Do you share the projects you do?}

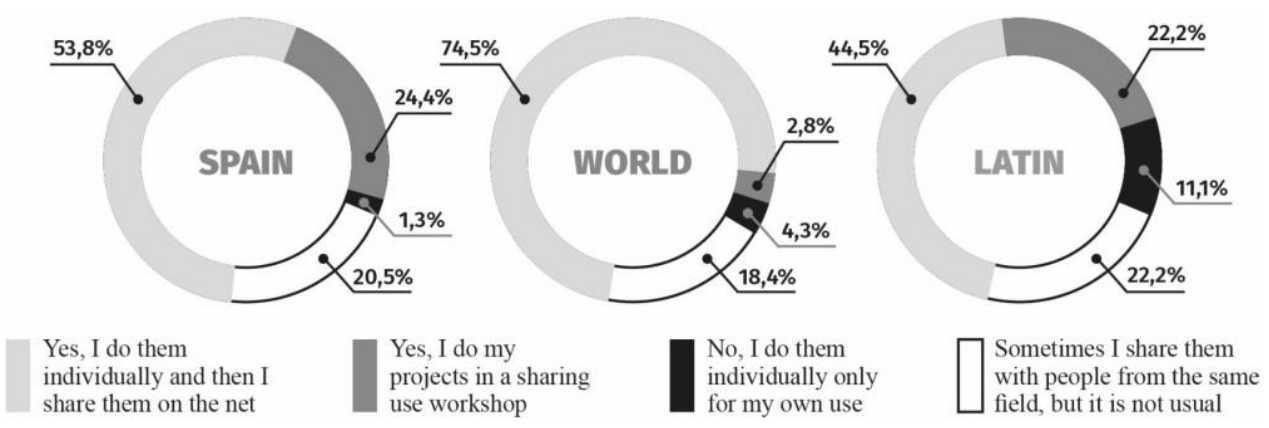

Figure 4. Ways to share projects.

\subsubsection{What is your main objective as a maker/designer?}

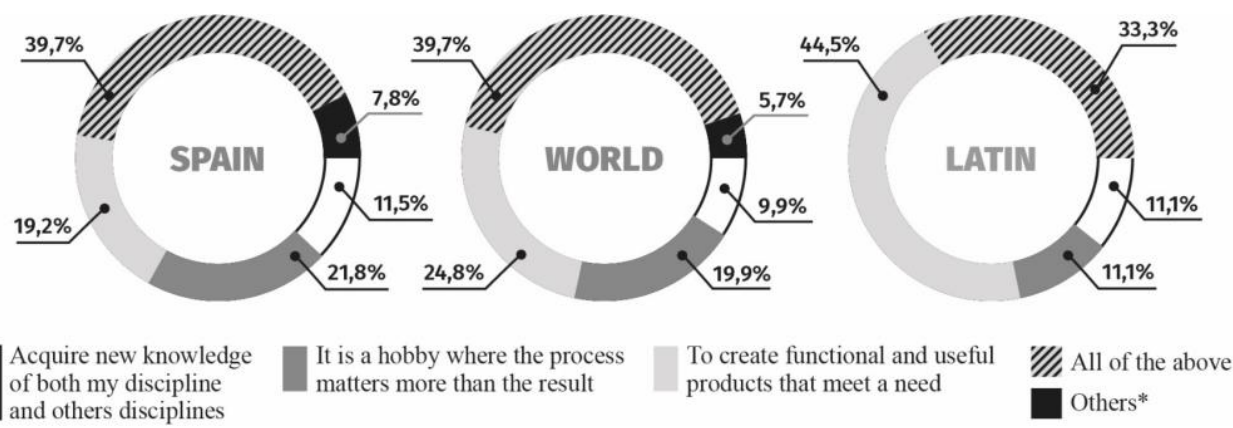

Figure 5. Main goals of prosumers. 


\subsection{Definition and use of modular design}

The results of the survey dealing with the definition and use of modular design are presented below.

\subsubsection{Do you know what "modular design" is?}

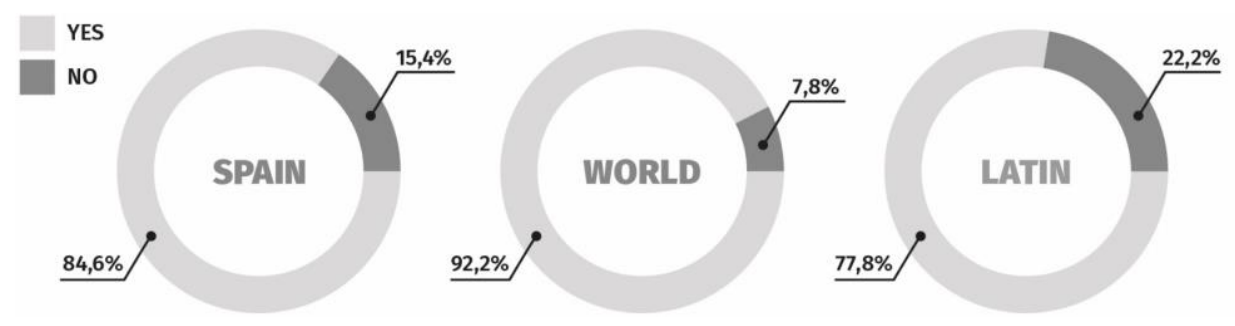

Figure 6. Knowledge of the term "modular design".

\subsubsection{If so, which of the following characteristics do you think best describe it?}

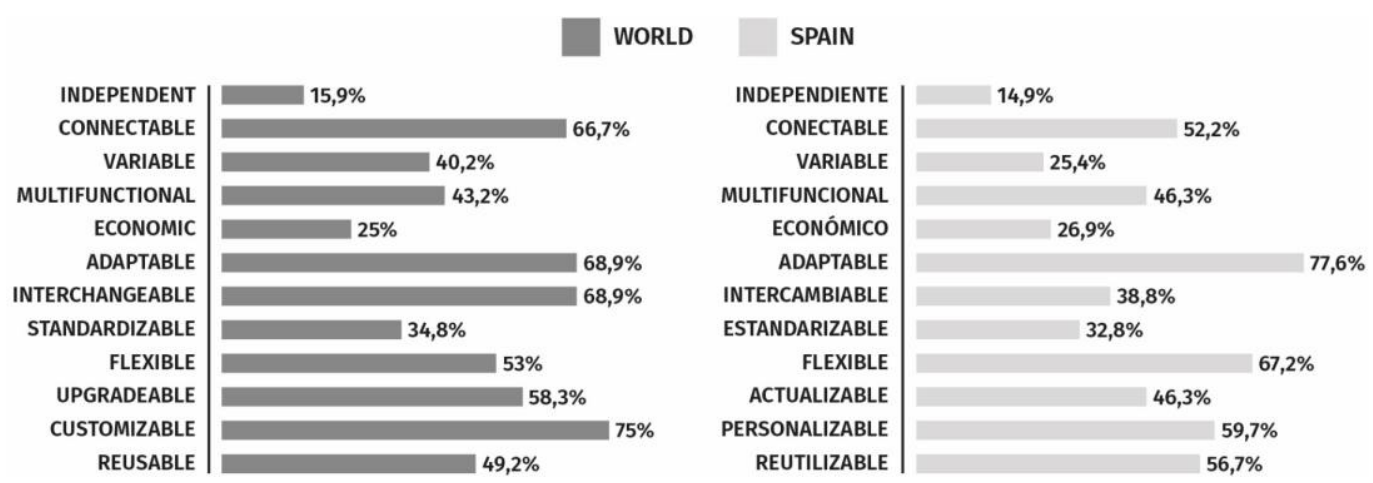

Figure 7. Characteristics that describe modular design.

The features that respondents most associate with modular design are adaptable, customizable and connectable, while those that least are independent, economic and standardizable. The results of the Latin American version are not included in this question as it is a very small and not representative sample (7 answers) compared to the national (67) and world (134) version.

\subsubsection{Have you ever used modular design to create or modify a product?}
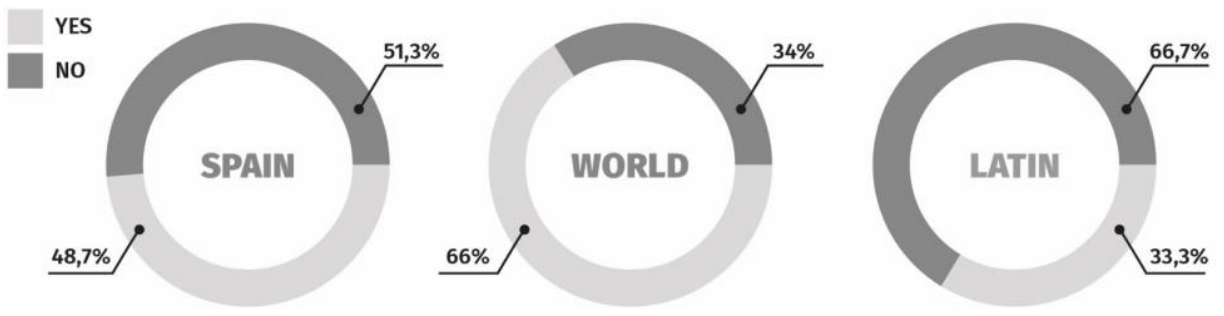

Figure 8. Use of modular design by respondents.

\subsubsection{How did you apply it?}
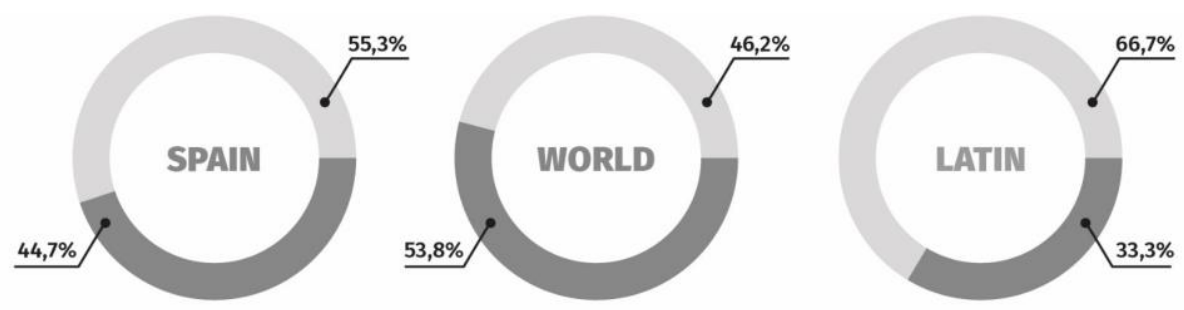

Premeditated, as it was a project specification from the beginning

It emerged as a solution to a problem or need during the development of the project

Figure 9. Ways to apply modular design in product design. 
The respondents had previously applied modular design in numerous types of products such as supports, prosthetics, furniture, architecture, automotive, robots, toys, 3D printers and home automation, among others. On the other hand, some of the main reasons for its application were: adaptation to the end user, future updates, customization, product variety, multifunctionality and product flexibility.

\subsection{Application of product design methodologies}

The following sections expose the results about the application of product design methodologies.

\subsubsection{Which of the following work methods do you use most frequently?}

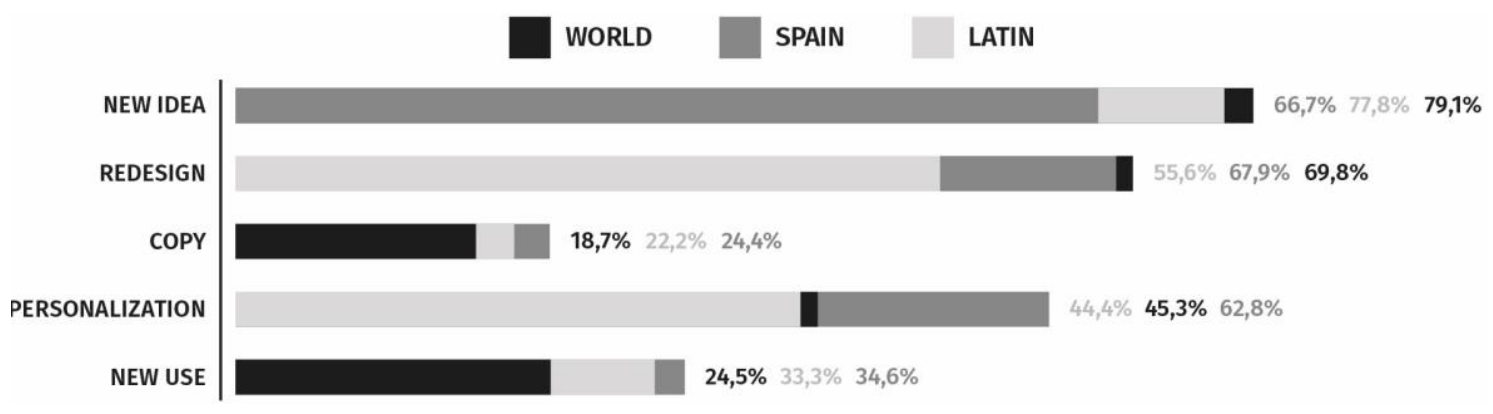

Figure 10. Most frequently used working methods.

The most used methods are new ideas, redesign and customization. Other respondents also stated that they were based on the combination of existing ideas or products.

\subsubsection{Do you follow any design methodology to create your own products?}
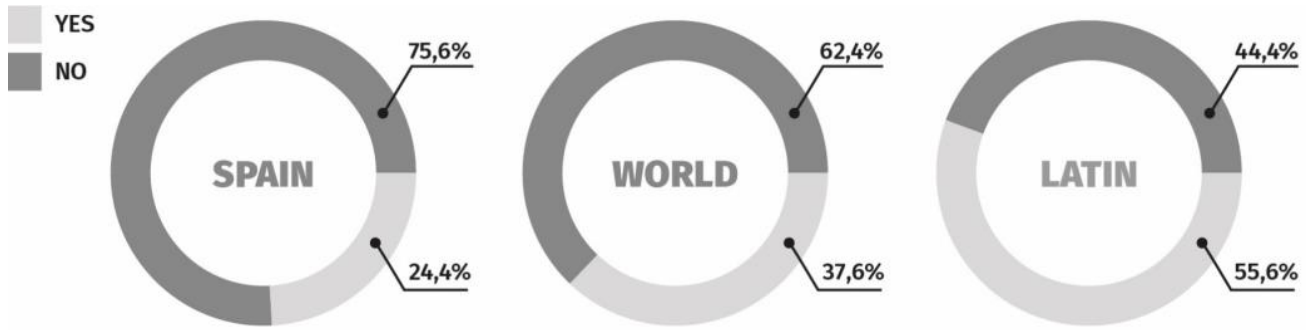

Figure 11. Use of design methodologies to create products.

Some of the more general design methods cited by respondents were: design thinking, research + development, function before form, inclusive design, eco-design, trial and error, bottom-up, user experience and the identification of needs.

\subsubsection{What aspects of the product do you work on?}
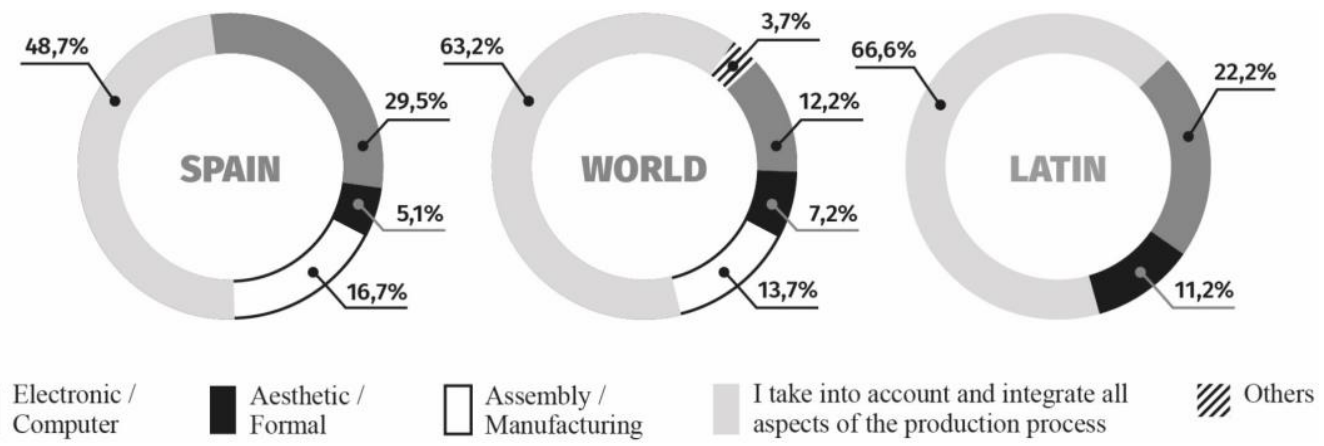

Figure 12. Aspects of the product most worked by the respondents.

As can be seen, the majority of respondents take into account all aspects of design and development of the products they work on, followed by those who only focus on the electronic/computer part. 


\subsubsection{Do you think that modular design could be an advantage in the development of your own}

products?
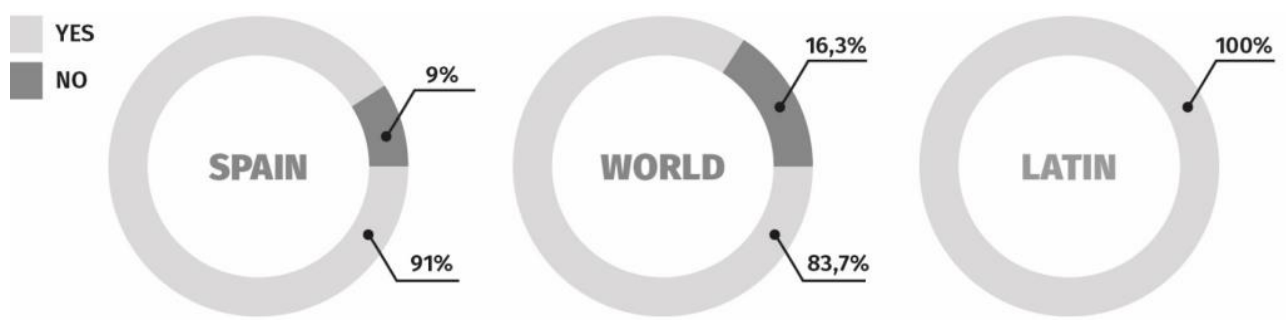

Figure 13. Advantages of modular design in product development.

\subsubsection{It there was a methodology to create your own modular products, would you use it?}
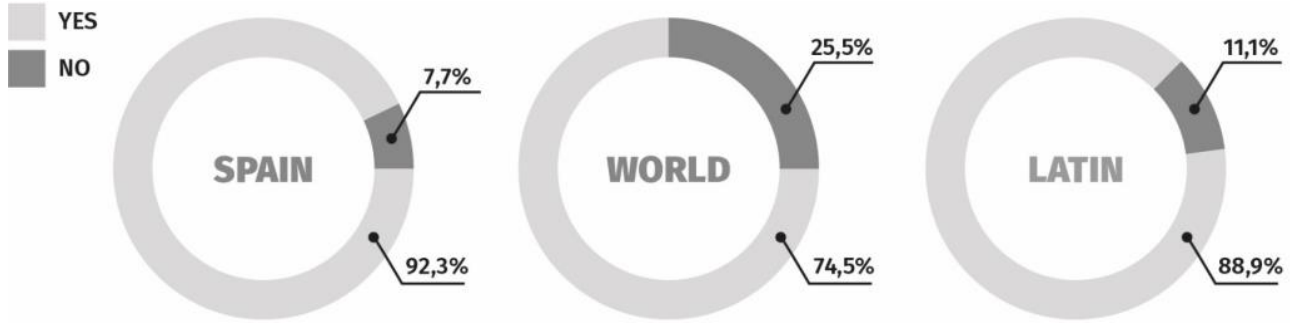

Figure 14. Potential use of a modular design methodology to prosumer.

Among the most cited reasons why respondents would use the described methodology are: functionality, saving time, flexibility, speeding up the process, more accessible design, facilitating innovation, creativity, customization, adaptation, interaction, durability and usefulness for non-specialized users.

\section{DIscussion}

The objective profile of respondents would be non-specialized users who intervene in the process of the products they consume to satisfy their needs and wants. Despite the fact that at the beginning the survey was only aimed at this profile because it was who would benefit from the result, it was necessary to take into account a more professional point of view. For this reason, the decision to include industrial and product design professionals in the survey profile was crucial to provide advanced knowledge of modular design and methodologies as well as increase the number of valid answers. As a result, in the world version $58 \%$ of respondents were designers and $37 \%$ were makers. In addition, it is also a type of user susceptible to using the methodological model because, despite the fact that the prosumer is not used to utilize design methodologies, a designer can use a methodology focused on prosumer.

The research outcome focuses on the prosumer user by including in the term all users who produce part of the products they consume, such as "makers". However, although the term is used in the academic field, its use is not frequent in the real field of application. In fact, as the survey shows, the term used instead is "maker" $(\sim 75 \%)$. In addition, the results show that more than half of those respondents have never heard of the term "prosumer" and only around $20 \%$ associate it with the meaning we give it in this research because it is a term with several meanings. This fact had already been identified during previous research, so the dissemination process was devised primarily with makers in mind. The reason is that they have a deeply rooted philosophy based on sharing knowledge, so communication between them is a fundamental pillar of their culture. This was of great help when it came to disseminating the survey, thus facilitating that it also reached prosumers with a lower level of communication than makers.

There is a certain confrontation between the terms maker and prosumer. Both coincide in their objective, but are far apart in the way of achieving it. While a prosumer intervenes in a product individually and without taking other prosumers into account, a maker has an opensource philosophy based on sharing and cooperating with others, which marks a clear contrast between the two terms. Can one term be encompassed within another? Initially, we consider "prosumer" as a general term that encompasses a wide scale of users including terms such us self-consumption (high level of intervention) or massive customization (low level of intervention). Along this scale would be makers, designers or hackers, among others. However, since there are coincidences and differences between prosumer and maker, 
could we consider prosumer as a specific maker that acts on its own? It is clear that both terms go hand in hand, but the question of whether one of them encompasses the other can lead to discussion. On the other hand, due to the terminological confusion and the theoretical definition of prosumer, it is difficult to know if we really know the current prosumers. In recent years, numerous terms have emerged to refer to these users. From the DIY movement to the maker trend, these currents arise in response to the technological and social context which affects the needs and way of working of the prosumer.

The goal that prosumers pursue when creating their own products is diffuse. In the three surveys, almost half of them ( $40 \%)$ seek to learn and be entertained while creating functional products. However, few of them create their own products only with the objective of learning $(\sim 10 \%)$, while it is more frequent that they do it as a hobby $(\sim 20 \%)$ or necessity $(\sim 20 \%)$. Despite this, the results have a great coincidence between the three surveys, so we can conclude that most prosumers seek to benefit from the different aspects that creating their own products offers: learning, entertaining and solving a need. It is also observed that the most common way to share projects is to do them individually and then upload them to the internet, something common in maker culture. However, $20 \%$ of surveyed say that they sometimes share it with people in the same field, but not regularly, which is more related to the prosumer habits. On the other hand, according to the results of the survey, the least common is that users do the projects individually and only for their own use, without sharing them later.

Prosumers and makers don't adopt design methods, proven to be valid and effective, probably because they don't use methods. This may be due to the fact that they are non-specialized users who create their own methods or unconsciously imitate others, so they don't consider that they follow a specific one. It could change with users who have a more theoretical base and a greater relationship with the use of methodologies, such as designers. Makers and prosumers have been observed to act with freedom and without rules, although they follow instructions as with the tutorials. If we try to establish a canon with a rigid methodological model, then we will fail. The survey shows conflicting results: users don't usually use methodologies, but most would be willing to use one based on modular design. Users may be willing to make the effort to use a new methodology in order to take advantage of its benefits and results. To ensure the success of the model, it should not only adapt to the needs and characteristics of prosumers and makers, but also generate great interest in them.

\section{CONCLUSIONS}

The results obtained in the survey can be considered totally valid and truthful mainly due to three factors. The first is that it has been answered by users related to the objective of the research (prosumers, makers and designers), so the answers are reliable because they are responded by users with experience in the field of application. The second is that there is a high level of agreement between the three surveys in most of the questions. Therefore, it can be concluded that there is a consensus according to the opinion of the respondents on the topics covered. In this regard, when comparing results, the version of the survey for Latin America has not been taken into the same consideration because it has a much lower response rate than the other two versions. And, finally, the third factor is that the different geographical origin of the respondents, and therefore the socio-cultural context, has not affected the results. This aspect was especially critical in the case of the worldwide survey, where it would have been more difficult to identify possible differences despite having recorded the country of origin of the respondents.

The percentage of users who knew about modular design was much higher than expected, being around $90 \%$ of those surveyed. In addition, its characterization was highly consensual, especially in the worldwide survey where it was associated with connectivity, adaptability, interchangeability and customization of the product. We can thus conclude that the respondents know how to recognize modular design and know its advantages in product design. In fact, more than half had ever used it to create or modify their own products in order to adapt, customize, update or add features, among other design goals. However, the way in which users use modular design is not clear, making it evident that there are two ways to do it: one as a design specification from the beginning of the project, and another as a tool that provides a solution to a problem that has arisen during its development.

The most frequently used work methods by prosumers are new ideas and redesign. These are methods that require more intervention on the product than in the case of personalization or copying. For this reason, we can affirm that prosumers apply creativity in the products they design to achieve new solutions through free intervention without restrictions. However, they are not used to using design methodologies to achieve this: only around $30 \%$ of those surveyed do so. Previous research, as well as 
feedback from respondents, support the fact that makers and prosumers follow a pattern to work. Despite not considering it as a methodology, the real application is based on observation, analysis, trial and error. The development of a methodological model for non-specialized users can be a great challenge when it comes to knowing if the end user would really be willing to use it. In this particular case, we found that the majority of respondents would not only use the method, but also think that modular design is an advantage for product design. Despite this, the model must be adapted correctly to them to ensure its correct usability and acceptance. For this, it is necessary to know how to interpret the responses obtained in this study. In this regard, we can see that users, despite not being very familiar with the use of design methodologies, are used to following instructions and guidelines, so the future model should be a hybrid that presents a methodology through of a series of steps. In addition, it should also be an easy method to understand by users who belong to different disciplines and are not specialists in product design.

In view of the survey results, modular design should be treated as a design specification in the methodological model, so that the end user takes it into account from the beginning of the project. Its use will be focused mainly on the conceptual design phases, which are those in which the prosumer has greater freedom of intervention on the product and where they can apply a higher level of creativity. On the other hand, we found that more than half of those surveyed take into account all aspects of the product, including its electronics, aesthetics, manufacturing and assembly, among others. This means that they are interested in being involved in the entire design process, which is why the future methodological model shouldn't be focused on a single aspect. Finally, it should be noted that the model can also be used by designers. Thus, although not all prosumers are capable of interpreting and using a product design method, any designer should be able to use the methodological model to be developed.

\section{ACKNOWLEDGMENTS}

This study has been able to be carried out thanks to all those people, especially the maker community, who have dedicated their time to carry out this survey and have collaborated in its dissemination.

\section{REFERENCES}

AlGeddawy, T. and ElMaraghy, H. (2013), "Reactive design methodology for product family platforms, modularity and parts integration", CIRP Journal of Manufacturing Science and Technology, CIRP, Vol. 6 No. 1, pp. 34-43. http://dx.doi.org/10.1016/j.cirpj.2012.08.001

Asión-Suñer, L. and López-Forniés, I. (2019), "Modular Design: Product Design Opportunities and a Case Analysis", Advances on Mechanics, Design Engineering and Manufacturing II, Springer, pp. 596-609. https://doi.org/10.1007/978-3-030-12346-8_58

Asión-Suñer, L. and López-Forniés, I. (2020), "Prosumer and Product Design Through Digital Tools", Lecture Notes in Mechanical Engineering, pp. 23-30. https://doi.org/10.1007/978-3-030-41200-5_3

Fairphone. (2020), "Fairphone”, available at: https://www.fairphone.com/es/ (accessed 12 April 2020).

Favi, C. and Germani, M. (2012), "A method to optimize assemblability of industrial product in early design phase: From product architecture to assembly sequence", International Journal on Interactive Design and Manufacturing, Vol. 6 No. 3, pp. 155-169. https://doi.org/10.1007/s12008-012-0147-y

den Hollander, M.C., Bakker, C.A. and Hultink, E.J. (2017), "Product Design in a Circular Economy: Development of a Typology of Key Concepts and Terms", Journal of Industrial Ecology, Vol. 21 No. 3, pp. 517-525. https://doi.org/10.1111/jiec.12610

Maker Faire Bilbao. (2019), "Maker Faire Bilbao", available at: https://bilbao.makerfaire.com/

Papavlasopoulou, S., Giannakos, M.N. and Jaccheri, L. (2017), "Empirical studies on the Maker Movement, a promising approach to learning: A literature review”, Entertainment Computing, Elsevier B.V., Vol. 18, pp. 57-78. https://doi.org/10.1016/j.entcom.2016.09.002

Souza, T. and Sato, L. (2019), "Educational Robotics Teaching with Arduino and 3D Print Based on Stem Projects", 2019 Latin American Robotics Symposium (LARS), 2019 Brazilian Symposium on Robotics (SBR) and 2019 Workshop on Robotics in Education (WRE), IEEE, pp. 407-410. https://doi.org/10.1109/LARS-SBR-WRE48964.2019.00078

Swidget. (2020), "Swidget", available at: https://www.swidget.com/ (accessed 12 April 2020).

Toffler, A. (1980), The Third Wave, The Ultimate Business Library, Wiley, Wiley.

You, Z.-H. and Smith, S. (2016), “A multi-objective modular design method for creating highly distinct independent modules”, Research in Engineering Design, Springer, Vol. 27 No. 2, pp. 179-191. https://doi.org/10.1007/s00163-016-0213-8

Zheng, P., Xu, X., Yu, S. and Liu, C. (2017), "Personalized product configuration framework in an adaptable open architecture product platform", Journal of Manufacturing Systems, The Society of Manufacturing Engineers, Vol. 43, pp. 422-435. https://doi.org/10.1016/j.jmsy.2017.03.010 